\title{
Innovative Education as a Factor of Professional Mobility Formation with the Students of Economic Specialties
}

\author{
Lyudmila Valeryevna Shelekhova ${ }^{1}$, Zaurbiy Uchuzhukoich Blyagoz ${ }^{1}$, Aslan Vladimirovich Nagoev $^{1}$ \& Valeriy \\ Aslanovich Teshev ${ }^{1}$ \\ ${ }^{1}$ Mathematical Methods and Information Technologies Department, Adyghe State University, Maykop, Russian \\ Federation
}

Correspondence: L.Shelekhova, Pervomaiskaya str., 208, Maykop, Russian Federation.

$\begin{array}{lcc}\text { Received: February 28, } 2015 & \text { Accepted: March 20, } 2015 \quad \text { Online Published: April 24, } 2015 \\ \text { doi:10.5539/res.v7n6p54 } & \text { URL: http://dx.doi.org/10.5539/res.v7n6p54 }\end{array}$

\begin{abstract}
The article analyzes the phenomenon of economic students' professional mobility. It studies different approaches to the problem of professional mobility and the conclusion is the following: professional mobility is simultaneously a personal trait, which provides a person with the grasp in the changeable professional surrounding, a type of activity, directed at the professional self-development, and a transforming process creating the inner and the outer professional environment. It's stated that one of the most important factors in professional mobility formation is the innovative education and application of innovative educational technologies. In the context of forming the economic students' professional mobility, such an innovative technology as project-based learning is studied. The paper also presents a program of diagnosing those competences, which are necessary to acquire in the process of professional mobility forming, including personal competences such as axiological, personal, self-regulation, social-communicative and intellectual competence. The above-mentioned program allowed making a conclusion about the effectiveness of forming economic students' professional mobility by using the project-based teaching methods.
\end{abstract}

Keywords: professional mobility, social-professional mobility, innovative education, innovative educational technologies, interactive teaching methods, project-based method, projects-based learning, competences

\section{Introduction}

Nowadays radical changes in the social sphere and labor market have led to the quality changing of the requirements for the universities graduates' professional status - this is true about future economists as well. To gain professional success and relevance, the person must have certain personal traits such as flexibility, being ready for changes, ability to assimilate to the new conditions - in one word, one must have mobility. In connection to this, the task of the higher education institutions is to form the professional mobility as a specific trait of a competitive person, which helps the specialist to adapt to the unstable market conditions of the professional activity. This, in turn, has initiated the appearance of new educational process requirements. Correspondingly, the category of professional mobility (PM in the further text) is introduced in the scientific terminology due to the life demands themselves: non-stop changing of the labour market situation makes the universities graduates work hard at constant qualifications development, at knowledge gaining and at self-education (Mannikova, 2009).

In its broad sense, mobility is defined as the assemblage of abilities to move, to act, to do the tasks. Some authors explain mobility as the ability of a person to find oneself quickly in the unknown surrounding and the skill to implement the necessary activity forms there (Zvereva, Shevchenko, \& Katkova, 2006). In their opinion, the presence of this personal trait is expressed in his/her energy, making right choices, giving objective evaluation of one's possibilities, aspiration to be a success. At this, the majority of research papers differentiate professional and social forms of mobility (Patrick \& William, 2007), which are sometimes seen as a wholesome category "social-professional mobility" (Dementieva, 2009; Kalinovsky, 2001).

Dementieva supposes that social-professional mobility (SPM further in the text) is an integrative personal trait, which lets one remain a socially active, competitive, professionally competent personality, good at self-actualization, development and activity changes in the changing conditions, including the changes, which occur after a university graduation (Dementieva, 2009). 
Kalinovsky agrees with this and sees SPM as an integrative personal trait, which stipulates the person's ability to change the social, cultural or professional status/position quickly under the influence of changing circumstances in the society, culture or professional sphere (Kalinovsky, 2001).

PM proper is described in scientific works as the individual's abilities and willingness to study the new techniques and technologies quickly and efficiently, to do new production tasks, to acquire lacking knowledge and skills ensuring the effectiveness in the new kinds of professional activity (Dyachenko \& Kandybovich, 2004; Zeer, 2003).

According to Goryunova's idea, PM is expressed simultaneously in the personal traits, which activate the internal personal mechanism of development; in the activity, which is determined by the changing environment and as a result, the person is self-actualized in his/her profession; it is also expressed in the process of individual's transformation of oneself and his/her professional surrounding. Generally speaking, L. V. Goryunova describes PM as a personal trait, directed at self-transformation and environment transformation according to the existing development tendencies (Goryunova, 2007)

E. R. Ipatova thinks that PM is expressed in the person's being ready to change his/her professional activity very promptly, and this readiness should be characterized by enthusiasm and interest to the new professional sphere, assimilation to its various forms and by the creative attitude to the new kind of activity (Ipatova, 2012).

According to M. V. Kormiltseva, PM is an "integrative construct", which allows the person to find oneself effectively in the changing professional conditions such as changing of the profession, changing of the professional status or the position, advanced training, mastering innovations in the technology and technique. This 'construct' also helps to support the effective interpersonal relationship in the professional (Kormiltseva, 2009).

Integrative character as a key PM feature is also mentioned by R .Z. Balyagova, who defines PM as 'an integrative personal trait' uniting the formed internal personal need to have this mobility as well as the person's ability to be professionally mobile and to realize this PM reflectively (Balyagova, 2012).

O. A. Kipina considers PM to be a dynamic personal characteristic, expressed by the ability to assimilate successfully in the changing professional conditions as well as to be ready to change these professional conditions and fulfill self-development and self-realization in the working process. This author suggests the following PM structure:

1) The person's active position, which is demonstrated by self-transformation and environment transformation and by the ability to set reachable goals and follow the program of their achievement;

2) The person's adaptive ability which allows to assimilating effectively in the changing conditions of professional activity;

3) The person's creativity, which leads to the creative, constructive attitude to the outer surrounding and one's own activity implementation, to the readiness to transform them purposefully and appropriately (Kipina, 2009).

According to the foreign scientists (Plewis \& Bartley, 2014), the base for the PM and graduates' competitiveness formation must be made of so-called "key qualifications", characterized by a wide range of impact and being out of the identical professions frame, which prepare the future specialist for the possibility of changing his/her previous profession and mastering a new one.

Observing the real life, some authors, e.g., D. V. Chernilevsky, suppose that being professionally mobile means, first, being competitive at the labour market. Universities graduates' PM is formed by a complex training, which has to combine both narrow professionalism and universalism. In the author's opinion, this is explained by the necessity to replace the purely producing skills and abilities by their broad assemblage, including the knowledge and skills directed at health care, cultural traditions development and preservation, nature resources rational usage, environmental protection etcetera (Chernilevsky, 2002).

Summarizing the above-mentioned ideas, we can conclude that mobility is the integral dynamic personal characteristic, which provides the individual's integration into a non-stop changing life conditions. If judged from the professional genesis point of view, PM as a personal trait has a great value as a feature, which guarantees the understanding of the changing professional circumstances; as a kind of activity, directed at the professional self-development as well as at the transformation process of oneself and the outside professional environment.

Minding the PM complexity, which includes both psychological and dynamic components (activity, assimilation, creativity), a professionally mobile person can be defined as a personality, who acts adequately according to 
professional and social demands, who is ready to implement key basic and special competences acquired at the university, who reacts immediately to the changing professional conditions, solves the most complicated professional tasks effectively and who is at the same time responsible for one's work results and self-developing.

\section{Methods}

When studying the conditions of universities students' PM formation it is necessary to emphasise that the researchers have analysed the pedagogic conditions guaranteeing PM formation, and education has been called the most essential of them. It's exactly in the teaching process where the student's personal growth is stimulated, his/her knowledge is enriched, the interests are formed and the skills are developed.

At the same time, according to some scientists, the professional education has the following tasks:

Firstly, education must produce the specialists able of fast assimilation in the changing conditions of professional activity, interested in self-perfection and self-education. Correspondingly, the system of professional education must promote the students' assimilating abilities and self-educational skills in the teaching process.

Secondly, education has to form such personal characteristics of the future professional, which would help him to gain professional growth independently (Sicherman, 1990).

S. E. Kaplina has instantiated those pedagogical conditions, which lead to PM formation (basing on the conducted theoretical and experimental study):

1) Development of the students' motivation in PM formation, stimulating them to personal and professional self-development, self-cognition, self-upbringing and self-perfection;

2) Methodical base of the students' PM formation process (programs, textbooks, methodic recommendations, special courses, etc.), which part is a specially developed didactic professionally-integrated communicative technology, promoting the PM formation;

3) Interdisciplinary integration of naturally-scientific, technically-applied and humanitarian knowledge to develop the students' personality as a base for future specialists PM formation;

4) Necessity for the university teachers to master the corresponding knowledge concerning the methods and content of PM formation;

5) Creation and realization of the scientifically-explained future specialists' PM formation model, corresponding to the specialty demands (Kaplina, 2008).

Thus, nowadays the science has fully studied the assemblage of pedagogical conditions of university graduates' PM formation. Still, in our opinion, the main thing for the higher institution is not only observing the pedagogical conditions for PM formation as they have the outside character in relation to the set task but also, and primarily, the necessity of the students' upbringing as if they're the subjects realizing their PM formation. The latter causes the need for the creation of such pedagogical conditions that would attract the personal activity of the learner to use his personal resources.

One of the effective ways of solving these problems is the application of innovative educational technologies.

Innovations and corresponding innovative processes are applied today practically in all the spheres of human activity, which makes essential to study these phenomena integrally and understand them. This is true about the professional education. The primary condition of modern economic systems stable development is making the innovative factor maximum. It's the innovative activeness in the economics, which defines to a great extent the economic growth and labour efficiency in the leading world countries. Education plays the role of provision factor for the innovations introduction process and creates all the necessary conditions, premises and intellectual background for it.

Innovative education not only protects the youth socially in the situations of unpredictable changes at the labour market. It also guarantees the creation of stable base for constant professionalism increase, offers additional opportunities for the new highly qualified personnel in various sectors of economic activity.

If applied to the educational process innovation is defined as the earlier unknown aspect in the process of education renewal. Educational innovation is a drastically different approach on the base of a new idea, which changes the existing educational technologies dramatically and defines the new type of the educational organization. This way, innovative technologies in the educational process are the invention of some new component for the educational system. Innovative educational projects are the main resource of changing into a new modern educational system, modernizing the national educational system as a whole. Innovations in the 
professional education consist of scientific and theoretic knowledge with a certain degree of novelty, new effective educational technologies ready to be implemented.

It's necessary to mention two most important conditions ensuring innovations and innovative activity in the process of professional education.

The first condition connected with the educational system itself supposes the following: firstly, the necessity of gradual introduction of the innovative methods and methodic creation experience into the professional educational structure; secondly, the necessity to master the skills of managing the innovative activity and innovative education development among the university staff.

The second condition is in the close connection with the state governmental educational program and it should be directed at the state and social support of the programs and projects of innovative professional education.

Innovative educational technologies are the result of educational process, organized in such a way that basically different principles, means, methods and technologies are used. Theses allow reaching the educational effect consisting of maximal creative activity, mastering the professional competences and a wide spectrum of practical skills (Polat, 2002).

In connection with this, the main components of the innovative educational project, which are to be developed, are the following: setting the goals of innovative education; preparation of the studying materials and the development of teaching procedures of innovative education; the development of the materials for the current and final assessment and the innovative education results correction.

So-called interactive teaching methods can be named among the innovative educational technologies, which are especially popular nowadays. In the researchers' opinion, modern educational methods must be based on the interactive character of education because it's the interactivity of cognition which correlates mostly with the peculiarities of a modern person's thinking specifics. In connection to that, interactive methods develop the personal intellectual and creative potential of future institution graduates maximally. In the conditions of interactive education, the students get a high level of assimilation formed. The future specialist can solve communicative and professional tasks and is ready for various changes in his/her professional activity basing on the acquired knowledge, skills and competences (Sicherman, 1990).

Let's speak about the most famous and widely used interactive methods of teaching nowadays.

First, they are business and role games which script allows recreating the professional situations, modeling the professional activity sphere. The student appears in this sphere and realizes the necessary character of the knowledge and skills, which he gets; he/she starts to perceive them as integrational, disconnected from certain disciplines (Antsiferova, 2013).

The portfolio fixes individual achievements of the students, includes them into the description of creative projects and researches (theses, articles, etc.), main achievements in the educational activity (conferences, contests, practical trainings, etc.). The portfolio can be enriched by the teachers' references and their evaluation of the students' works (Shelekhova, 2008).

Another interactive teaching method is a case-study, consisting of initial problem discussion as well as of "analyses, evaluation, independent choice of the problem solvation together with the composed scheme of its realization" (Evtyugina, 2012). At this, the practical situation itself brings to the actualization of a certain knowledge complex, which is necessary to apply when solving the given problem (Rozhnova, 2012). When the student is working at the case independently, he/she develops the abilities of analyzing socially-meaningful problems, abilities for evaluation, results interpretation and conclusions explanation. In the interaction process, the students develop the ability of cooperative colleague dialogue and the ability to work in a team. The polemic character of this technology forms the abilities of individual strategies and tactics of effective communication when doing certain professional tasks.

At present, the method of projects is the most popular of the whole bulk of interactive teaching methods. It demands quite a long period of time spent on doing the given task and a large amount of work done by the student independently (or in a group) under the supervision of the project responsible teacher-consultant.

The purpose of the project type teaching is to create the conditions giving the students a possibility to obtain the knowledge independently from various sources. With this, they're taught to use the gained information when solving different suggested practical problems, simultaneously getting communicative skills and abilities, working with different group mates. Using the projects method stimulates the students to develop systematic 
thinking and various research skills, connected with defining the problem, collecting information, observing, experiments conducting, analyses, hypotheses formulating, research results summarizing.

The initial theoretical positions of the project method, according to the researchers, are the following:

1) The attention is focused on the student, while the content of the project teaching is directed at his/her creative abilities.

2) The teaching process based on the projects relies not on teaching some subject but on teaching the activity, which makes certain personal sense for the student and which raises his/her inner motivation to learn.

3) The work on the project is done in the individual tempo, which guarantees every student the achievement of his/her development level.

4) The complex approach realization, when working at educational projects, stimulates equal development of the student's main psychological and intellectual traits.

5) Due to the universal usage of basic knowledge in various situations, their deep and conscious mastering is guaranteed (Zhak, 2001).

The project method implementation in the teaching process suggests the following algorithm of cooperation between the teacher and the students:

- Project task development.

- Development of the project itself.

- Registration of the activity results.

- Public presentation of the project.

- Reflection.

Making any project within the project-type educational process suggests getting some qualitatively new results at the end. These results can be expressed by various students' abilities development and their independence in the studying process.

\section{Results}

When defining the requirements for the institute's graduates, a competence approach is often used nowadays. Here competence is defined both as a personal ability of the graduate to do certain professional tasks and as the requirements concerning his/her personal and professional traits.

In connection to this, the effectiveness of project-teaching usage in the process of PM formation with the economic students was evaluated according to the level of their competences, which were necessary to master when forming PM:

1) Personal competences, reflecting their readiness to mobilize the inner potential in the situations connected with PM, including the following:

- Axiological competence, which is the skill to choose target and sense purposes in life - it was estimated by means of methodic of E. B. Fantalova "Basic necessities of a person and the degree of their satisfaction";

- Personal competence which is the readiness to actualize and solve the appearing problems, the ability to realize one's personal potential - it was estimated by means of methodic T. A. Ratanova and N. F. Shlyakhtaya "Readiness for self-development" and of V. I. Andreeva " Ability to self-develop and self-educate";

- Self-regulation competence which supposes the mastering of methods of overcoming life difficulties-it was assessed by means of a questioner test of Aizenk "The level of emotional stability".

2) Social-communicative competence giving the possibility to build positive relationship with others, the skills of working in a team-it was assessed by means of V. V. Sinyavsky and B. A. Fedorishin's test "Communicative and organization skills".

3) Intellectual competence connected with the criticism of thinking and creativity, the ability to analyze the situations flexibly and fast - it was estimated by means of the methods of L. R. Kettell and V. I. Andreev's tests "The level of a person's creative potential", tests of L. Y. Gozman, M. V. Kroz, M. V. Latinskaya: Creativity and cognitive abilities".

Diagnosing the level of the above-described competences was conducted before and after finishing the formation work with the application of project method in the process of teaching the experimental group of students. 
The obtained results of the research were evaluated in the matter of quality and quantity by means of data statistic processing according to the Student's criteria.

\section{Discussion}

The data analyses conducted after diagnosing before and after PM formation with the economics students by means of the projects method has shown that all three competences demonstrated much more positive changes in the experimental group in comparison to the control group (in average $20-25 \%$ in each of the methods). The importance of the demonstrated results was confirmed by the statistics processing of the data according to the Student's criteria.

Therefore, the application of the project teaching method has led to the increase of personal competences level including axiological competence, personal competence and self-regulation competence as well as social-communicative and intellectual competences.

Thus, we can state that the data obtained by the end of formation work give us the chance to assert that using the project method as an innovative educational technology in the process of forming the economic students' professional mobility is rather effective.

\section{Conclusion}

One can conclude that the modern stage of Russian society development, marked by the drastic changes of state politics in the educational sphere has generated a need in formation and development management of the graduates' professional mobility. At this, the professional mobility means not only managing the graduates' professionalism perfection, based on the activities change but also projecting and realization of the integrated educational process, based on the innovative educational technologies implementation.

Nowadays the emphasis in the higher education has to be made on forming the wish and ability to act professionally and successfully. This quality can be formed on the base of confidence in the obtained professional knowledge, creativity and thinking system, the ability to find oneself in the changing conditions by means of realization of intellectual skills obtained at the university, which makes the base of future specialists' professional mobility.

Thus, the main didactic tasks of the present higher education system are training the graduates to self-educate in the professional sphere, to raise their interest in the studying process, to form the cognitive demands, abilities, skills of independent study in the context of their future profession. Solving these problems is possible only when teaching on the base of innovative technologies. To develop the education, to raise the competitiveness of the home economic and to take the proper place at the world market it is necessary to reform the system of education in such a way that the introduction of new education technologies and education informatization will become priorities.

\section{References}

Antsiferova, O. N. (2013). About role-games at a practical university class. In Social-cultural sphere in Russia: Society, education, language (p. 185). Ekaterinburg: Azhur.

Balyagova, R. Z. (2012). Pedagogical conditions of professional mobility formation with future specialists of oil and gas industry in the college educational system ( $\mathrm{PhD}$ thesis). Yoshkar-Ola.

Chernilevsky, D. V. (2002). Didactic technologies in higher school (p. 437). Moscow: YINITI.

Dementieva, O. M. (2009). Formation of social-professional mobility of the students in professional colleges $(\mathrm{PhD}$ thesis). Moscow.

Evtyugina, A. A. (2012). Communication and case-study method in professional education. Humanities and social science, 160(4), 60-65.

Goryunova, L. V. (2007). The components of professional mobility of a modern specialist. Higher education institutions news (Povolzhsky region), 1, 63-69.

Horan, P., \& Stout, W. (2007). Structure and process in occupational mobility. Social Science Research, 6(2), 170-187. http://dx.doi.org/10.1016/0049-089X(77)90006-0

Ipatova, E. R. (2012). Formation of social-professional mobility of university students (PhD thesis). Shuya.

Kalinovsky, Y. I. (2001) Development of social-professional mobility in the context of socio-cultural educational policy of the region (PhD thesis). Saint Petersburg. 
Kaplina, S. E. (2008). Conceptual and technological base of professional mobility formation with future engineers in the process of humanitarian disciplines study. Cheboksary.

Kipina, O. A. (2009). Professional mobility of a teacher. Pedagogical education and science, 1, 81-84.

Kormiltseva, M. V. (2009). Socio-personal competences of students as a factor of their professional mobility ( $\mathrm{PhD}$ thesis). Ekaterinburg.

Mannikova, Y. S. (2009). Socio-professional mobility of the youth in the integrated system "college-manufacture". Educational integration, 1, 101-103.

Nuzhnova, S. V. (2007). Theory and practice of training the students' professional mobility at the provincial colleges. Chelyabinsk: CSU.

Plewis, I., \& Bartley, M. (2014). Intra-generational social mobility and educational qualifications. Research in Social Stratification and Mobility, 36, 1-11. http://dx.doi.org/10.1016/j.rssm.2013.10.001

Polat, E. S. (2002). New pedagogic and informational technologies in the educational system. Moscow: Academy.

Rozhnova, K. O. (2012). Case-study as a way of communicative competence formation with the students-entrepreneurs. Socio-cultural environment in Russia: Society, education, language (p. 134). Ekaterinburg: Azhur.

Shelekhova, L. V. (2008). Portfolio as one of the forms of educational activity organization aiming at the student's individual trajectory in the XXI century (pp. 332-336). Rostov-on-Don.

Sicherman, N. (1990). Education and occupational mobility. Economics of Education Review, 9(2), 163-179. $\mathrm{http} / / / \mathrm{dx}$.doi.org/10.1016/0272-7757(90)90044-6

Zeer, E. F. (2003). Psychology of professions (p. 336). Moscow: Academic project.

Zhak, D. (2001). University education: From effective teaching to effective study: Reports on higher school didactic collection. Organization and control of projects work (pp. 121-140). Minsk: Propilei.

Zvereva, N. A., Shevchenko, S., \& Katkova, O. (2006). Graduate's training aimed at social and professional mobility. Higher education in Russia, 6, 89-93.

\section{Copyrights}

Copyright for this article is retained by the author(s), with first publication rights granted to the journal.

This is an open-access article distributed under the terms and conditions of the Creative Commons Attribution license (http://creativecommons.org/licenses/by/3.0/). 